\title{
Research on Performance of Asphalt Mixture from Central Plant Hot Recycling with Fly Ash
}

\author{
Ping Wu \\ Chang'an University\& Road and Bridge Limited Liability Company of Inner Mongolia, Xian\&Hohhot, \\ China \\ skdppt@163.com
}

Keywords: road engineering;regeneration mixture;fly ash;road performance

Abstract. Based on the concept of low carbon environmental protection, the used asphalt mixture was recycled and measured to determine the asphalt content of $3.8 \%$, and to determine the regeneration mixture gradation of AC-20,the optimum asphalt content of regeneration mixture was $4.9 \%$ determined by Marshall test,and then,fly ash was added to asphalt mixture from central plant hot recycling,the performance was studied with different mixing amount of fly ash,results showed that:the performance of regeneration mixture is improved by mixing fly ash,and with the increase of the mixing amount of fly ash,the improving effects of high temperature anti rutting resistance and low temperature stability and water stability and fatigue resistance of regeneration mixture are more obvious.

\section{Introduction}

By the end of 2014, China's highway traffic mileage has reached 111900 kilometers and will be increasing,however,frequent renovation and reconstruction of high-grade asphalt pavement,tens of millions of tons of old asphalt mixture will be produced every year, recycling old asphalt mixture has become the key way to solve this problem.From Europe and the United States and other developed countries, the study on the regenerative asphalt mixture is in relatively lags behind,compared with the new material,plant mixed hot regeneration mixture shows some deficiencies, such as high temperature rutting resistance and resistance to water damage.Therefore, in order to improve the performance of regeneration mixtures,and mixing fly ash, which not only expands the approaches of the recycling of fly ash,but also is good to the sustainable development of the country.At present our country has not yet been about the study of fly ash used in regeneration mixture, therefore, it is necessary to study the performance of regeneration mixture mixed with fly ash to provide technical basis for the application of fly ash in the recycling asphalt mixture .

In view of the above problems, this paper written for the recycling of waste asphalt mixture,determining the asphalt content,and regeneration mixture gradation will be determined according to the old material gradation,through Marshall test, the best dosage of asphalt of regeneration mixture will be determined too,on this basis, through high-temperature rutting test, low-temperature bending test and immersion Marshall test and freeze-thaw splitting test and four-point bending fatigue test,the road performance of regeneration mixture with different dosage of fly ash will be studied,and it will lay the foundation for fly ash in application of the recycling asphalt mixture.

\section{The mix proportion design of asphalt mixture from central plant hot recycling}

The old asphalt mixture of Shannxi highway pavement was milled by a milling machine, after crushed and dried,the asphalt content of which was 3.8 percent measured by centrifugal extraction instrument,and the gradation of old asphalt mixture was determined by by standard sieve, and the concrete results were listed in Table 1. 
Table 1. Gradation of old asphalt mixture.

$\begin{array}{lcccccccccccc}\begin{array}{l}\text { Sieve } \\ \text { size } / \mathrm{mm}(\mathrm{mm})\end{array} & 26.5 & 19.0 & 16.0 & 13.2 & 9.5 & 4.75 & 2.36 & 1.18 & 0.6 & 0.3 & 0.15 & 0.075 \\ \begin{array}{l}\text { Passing } \\ \text { rate }(\%)\end{array} & 100 & 98.6 & 95.2 & 89.4 & 71.1 & 56.6 & 37.2 & 29.6 & 22.5 & 15.4 & 9.9 & 8.3\end{array}$

Recycled asphalt mixture aggregate gradation design is different from ordinary asphalt mixture, it is the original pavement aggregate and plus aggregate mixture, determine its engineering design gradation, should fully consider the highway grade, meteorological environment, factors such as traffic load, building materials supply, and fully successful experience for reference,AC-20 was used as the new gradation of asphalt mixture from central plant hot recycling, the gradation of regeneration mixture was listed in Table 2 to study on the influence law of fly ash on regeneration mixture.

Table 2. Design gradation of hot recycling mixture.

\begin{tabular}{|c|c|c|c|c|c|c|c|c|c|c|c|c|}
\hline $\begin{array}{l}\text { Sieve size } / \mathrm{mm} \\
(\mathrm{mm})\end{array}$ & 26.5 & 19.0 & 16.0 & 13.2 & 9.5 & 4.75 & 2.36 & 1.18 & 0.6 & 0.3 & 0.15 & 0.075 \\
\hline $\begin{array}{l}\text { Passing rate } \\
(\%)\end{array}$ & 100 & 96.8 & 84.2 & 75.4 & 61.1 & 46.6 & 32.7 & 22.5 & 16.1 & 10.4 & 7.2 & 5.3 \\
\hline
\end{tabular}

Refining of old asphalt mixture aggregate was more serious through comparison between Table 1 and Table 2, so the ratio of old asphalt mixture was $30 \%$, and then a new set of relatively aggregate was added for adjusting gradation of regeneration mixture to meet the requirements of design gradation.A conventional regeneration agent was used to improve the aging asphalt, and the best mixing amount of regeneration agent was identified as $5 \%$ according to test of aging asphalt.

According to the requirements of the design gradation of regeneration mixture,the dosage of asphalt was adjusted based on 5.0\%,forming Marshall specimen and measuring Marshall index,the asphalt content of $4.9 \%$ was identified as the best after calculating.

The quality of fly ash has little effect on the performance of the regeneration mixture according to previous research results, and the fly ash produced in a power plant in Xi'an was regarded as raw material,which was mixed in regeneration mixture to study on the performance of regeneration mixture with different dosage.

According to "Standard Test Methods of Bitumen and Bituminous mixtures for highway Engineering" (JTG E20-2011), the fly ash was added to regeneration mixture in the way of replacing mineral powder,and the content of replacing is $10 \%, 15 \%$ and $20 \%$ of the asphalt content,mixing the mixture and forming specimens, and tests of road performance were made with reference to test procedures.

\section{The influence of fly ash on performance of asphalt mixture from central plant hot recycling at high temperature}

Referencing to test procedures, the rut test of regeneration mixture was made, and the test results are shown in table 3.

Table 3. High temperature rutting test results of hot recycled asphalt mixture with fly ash

Types of Asphalt Mixture

General Plant Mixed Hot Regeneration Mixture(RAP of $40 \%$ )

Plant Mixed Hot Regeneration Mixture with Fly Ash (RAP of $40 \%$ )

$\begin{array}{lll}\begin{array}{l}\text { Dosage of fly } \\ \text { ash } / \%\end{array} & \begin{array}{l}\text { Dynamic } \\ \text { Stability/times/mm }\end{array} & \begin{array}{l}\text { Specification } \\ \text { Requirements }\end{array}\end{array}$

0

1421

10

1913

15

2368

20

3379 
According to table 3 , with the increase of dosage of fly ash, the dynamic stability of regeneration asphalt increases gradually, when the content reaches $20 \%$, the dynamic stability of regeneration asphalt mixture has increased 1.4 times, which shows that the addition of fly ash can significantly improve the high temperature performance of recycled mixture.

Compared analysis reason, the pore structure of fly ash is more compared with mineral powder, when added into the regeneration mixture, the pore structure of asphalt in the activity of the fly ash has strong adsorption effect, which can improve the asphalt consistency, improve the cohesive force of asphalt, so it can improve the high temperature performance of recycled mixture.

\section{The influence of fly ash on performance of asphalt mixture from central plant hot recycling at low temperature}

By low temperature bending test,the influence of fly ash on performance of asphalt mixture from central plant hot recycling at low temperature was studied,and the test results are shown in table 4.

Table 4. Low temperature cracking-resistance test results of hot recycled asphalt mixture with fly ash

\begin{tabular}{|c|c|c|c|c|}
\hline Types of Asphalt Mixture & $\begin{array}{l}\text { Dosage of Fly } \\
\text { Ash } / \%\end{array}$ & $\begin{array}{l}\text { Flexural Strength } \\
\mathrm{RB} / \mathrm{MPa}\end{array}$ & $\begin{array}{l}\text { Failure Strain } \\
u \varepsilon\end{array}$ & $\begin{array}{l}\text { Stiffness Modulus } \\
\text { SB/MPa }\end{array}$ \\
\hline Specification Requirements & -- & -- & $\geq 2000$ & -- \\
\hline $\begin{array}{l}\text { General Plant Mixed Hot Regeneration } \\
\text { Mixture(RAP of } 40 \% \text { ) }\end{array}$ & 0 & 8.11 & 2486 & 3262 \\
\hline $\begin{array}{l}\text { Plant Mixed Hot Regeneration Mixture } \\
\text { with Fly Ash(RAP of } 40 \% \text { ) }\end{array}$ & $\begin{array}{l}10 \\
15 \\
20\end{array}$ & $\begin{array}{l}8.94 \\
9.58 \\
9.99\end{array}$ & $\begin{array}{l}2636 \\
2776 \\
2798\end{array}$ & $\begin{array}{l}3391 \\
3451 \\
3570\end{array}$ \\
\hline
\end{tabular}

It can be seen from table 4 ,

(1) The failure strain of regeneration mixture increases with the increase of the dosage of fly ash, when dosage of fly ash reaches $15 \%$, increment of failure strain becomes smaller,but the failure strain has always been in rising,so that fly ash can improve the low temperature crack resistance of recycled asphalt mixture. This is because, the regeneration mixture mixed with fly ash, low temperature condition, the asphalt became hardened, hardened asphalt came into the pore of fly ash, and formed between the anchoring effect of fly ash,and which improves the fly ash particles and the adhesion strength of the asphalt, so it is good for improving the low temperature crack resistance of the recycled mixture performance.

(2) The stiffness modulus of regeneration mixture increases with the increase of the dosage of fly ash,which shows that the fly ash added to reduce the resistance to deformation capacity of the recycled mixture. This is mainly due to the fly ash having the pore structure, adsorption capacity is higher than the mineral powder, bitumen in oil by adsorption of fly ash comes into the pore structure, while increase the cohesive force of asphalt, but reduces the plasticity of asphalt, thereby reducing the resistance to deformation capacity of the recycled mixture.

\section{The influence of fly ash on water stability performance of asphalt mixture from central plant hot recycling}

The immersing Marshall test and freeze-thaw splitting test were conducted,in order to research of fly ash content on the water stability performance of regeneration mixture, the results were shown in table 5 and table 6. 
Table 5. Immersion Marshall test results of hot recycled asphalt mixture with fly ash

\begin{tabular}{|c|c|c|c|c|c|}
\hline Types of Asphalt Mixture & $\begin{array}{l}\text { Dosage of Fly } \\
\text { Ash } / \%\end{array}$ & $\mathrm{MS} 1 / \mathrm{kN}$ & $\mathrm{MS} / \mathrm{kN}$ & $\mathrm{MS} 0 / \%$ & $\begin{array}{l}\text { Specification } \\
\text { Requirement } \\
\mathrm{S}\end{array}$ \\
\hline $\begin{array}{l}\text { General Plant Mixed Hot Regeneration } \\
\text { Mixture(RAP of } 40 \% \text { ) }\end{array}$ & 0 & 7.54 & 8.52 & 88 & \multirow{4}{*}{$\geq 75$} \\
\hline \multirow{3}{*}{$\begin{array}{l}\text { Plant Mixed Hot Regeneration Mixture with } \\
\text { Fly Ash(RAP of } 40 \%)\end{array}$} & 10 & 7.98 & 8.72 & 91 & \\
\hline & 15 & 8.37 & 9.08 & 92 & \\
\hline & 20 & 8.46 & 9.09 & 93 & \\
\hline
\end{tabular}

Table 6. Freeze-thaw splitting test results of hot recycled asphalt mixture with fly ash

\begin{tabular}{llllll} 
Types of Asphalt Mixture & $\begin{array}{l}\text { Dosage of } \\
\text { Fly Ash/\% }\end{array}$ & RT1/kN & RT2/kN & TSR/\% & $\begin{array}{l}\text { Specification } \\
\text { Requirements }\end{array}$ \\
General Plant Mixed Hot Regeneration & 0 & 0.946 & 0.776 & 82 & $\geq 70$ \\
Mixture(RAP of 40\%) & 10 & 1.023 & 0.849 & 83 & 85 \\
Plant Mixed Hot Regeneration Mixture with & 15 & 1.114 & 0.947 & 86 \\
Fly Ash(RAP of 40\%) & 20 & 1.189 & 1.023 & 86 \\
\hline
\end{tabular}

From table 5 and table 6 it can be seen that the dosage of fly ash on the influence of residual stability and freeze-thaw splitting residual strength ratio has a same trend, the influence of residual stability and freeze-thaw splitting both increase with the increase of the content of fly ash, when $20 \%$ dosage of fly ash, the residual stability of regeneration mixture is $93 \%$, freeze-thaw splitting residual strength ratio is $86 \%$,it can be seen that fly ash on improving water stability performance of regeneration mixture has a significant effect.

\section{The influence of fly ash on water stability performance of asphalt mixture from central plant hot recycling}

With the help of fatigue test controlled by stress, the influence of dosage of fly ash on the fatigue test performance of regeneration mixture, and test results were shown in table 7.

Table 7. Fatigue test results of hot recycled asphalt mixture with fly ash

\begin{tabular}{|c|c|c|c|c|c|}
\hline \multirow{2}{*}{ Types of Asphalt Mixture } & \multirow{2}{*}{$\begin{array}{l}\text { Dosage of } \\
\text { Fly Ash } \% \%\end{array}$} & \multicolumn{4}{|c|}{ Fatigue life/times } \\
\hline & & $\mathrm{S}=0.25$ & $\mathrm{~S}=0.4$ & $S=0.5$ & $S=0.6$ \\
\hline $\begin{array}{l}\text { General Plant Mixed Hot Regeneration } \\
\text { Mixture(RAP of } 40 \% \text { ) }\end{array}$ & 0 & 67441 & 29481 & 13601 & 7369 \\
\hline \multirow{3}{*}{$\begin{array}{l}\text { Plant Mixed Hot Regeneration Mixture with } \\
\text { Fly Ash(RAP of } 40 \% \text { ) }\end{array}$} & 10 & 69454 & 38623 & 19489 & 8434 \\
\hline & 15 & 71987 & 39382 & 20996 & 9239 \\
\hline & 20 & 74318 & 41620 & 21061 & 10214 \\
\hline
\end{tabular}

According to the asphalt mixture fatigue theory, the stress controlled in the fatigue test, the stress and the fatigue life are in double logarithm linear relationship,analysis of the traditional s-n fatigue equation regression, the fatigue test results are non-linear curve fitting, the fitting results were shown in table 8 . 
Table 8. Fatigue regression equations and parameters of hot recycled asphalt mixture with fly ash

\begin{tabular}{llllll}
\hline Types of Asphalt Mixture & $\begin{array}{l}\text { Dosage of Fly } \\
\text { Ash/\% }\end{array}$ & Regression Equation & $\mathrm{k}$ & $\mathrm{n}$ & $\mathrm{R} 2$ \\
$\begin{array}{l}\text { General Plant Mixed Hot } \\
\text { Regeneration Mixture(RAP of 40\%) }\end{array}$ & 0 & $\mathrm{~N} \mathrm{f}=1331.740(1 / \mathrm{s}) 3.584$ & 1331.740 & 3.413 & 0.9999 \\
& 10 & $\mathrm{~N} \mathrm{f}=1856.959(1 / \mathrm{s}) 3.375$ & 1856.959 & 3.363 & 0.9999 \\
& 15 & $\mathrm{~N} \mathrm{f}=1968.756(1 / \mathrm{s}) 3.356$ & 1968.756 & 3.356 & 0.9999 \\
Plant Mixed Hot Regeneration & $\mathrm{N} \mathrm{f}=1586.875(1 / \mathrm{s}) 3.372$ & 1568.875 & 3.372 & 0.9999 \\
\hline Mixture with Fly Ash(RAP of 40\%) & 20 & & & & \\
\hline
\end{tabular}

It can be concluded by table 8 that to join in the regeneration mixture of fly ash, the fatigue performance of regeneration mixture is significantly improved, and after adding fly ash, and the sensitivity to applied stress is reduced.with the increase of dosage of fly ash,the value of $k$ of regeneration mixture is first increases then decreases, the value of $n$ is on the contrary, which show that excessive dosage of fly ash is not conducive to improve the fatigue performance of regeneration mixture, bu the fatigue performance of regeneration mixture with fly ash is better than without fly ash.

\section{Conclusions}

(1) Based on the rutting test, the influence of dosage of fly ash on the performance of hot regeneration asphalt mixture at high temperature has been studied,it shows that adding fly ash conductive to improve the high temperature performance of regeneration asphalt mixture, and the optimal dosage is $20 \%$.

(2) By low temperature bending test, the influence law of the dosage of fly ash to low temperature crack resistance has been determined that the low temperature crack resistance of regeneration mixture increases with, but the resistance to deformation ability decreases with the increase of the dosage of fly ash.

(3) The changing rule of residual stability and freeze-thaw splitting residual strength ratio of regeneration mixture has been analyzed.

\section{References}

[1] Jin-gui Wu. Discussion of Marshall mix design method of plant mixed hot recycled asphalt mixture,Highway. 011,(5):185-187.

[2] Yan-qing Xue, HUANG Xiao-ming. Experimental research on mechanical property of asphalt mixture from central plant hot recycling, Journal of building materials. 2011,14(4):507-511.

[3] Aravindak,Dasa. Pavement design with central plant hot-mix recycled asphalt mixes, Construction and building materials, 2007,21(5):928-936.

[4] Yan-qing Xue, HUANG Xiao-ming. Application and evaluation of asphalt mixture by central plant hot recycling in pavement structure with LSPM, Journal of hunan university (natural science edition).2011,38(10):26-33.

[5] JTG F41-2008, Technical specification for construction of highway asphalt pavements,Bei-jing:China Communications Press,2008. 